Noman 2015, 33(1), 69-78

Revista de Psicologia, Ciències de l'Educació i de l'Esport

ISSN: 1138-3194

Copyright (C) 2015

www.revistaaloma.net

\title{
L'ensenyament de la música tradicional i popular: una proposta multidisciplinària per al seu estudi
}

\author{
Maria Antònia Pujol i Subirà, Josep Gustems-Carnicer \& Caterina Calderón-Garrido \\ Universitat de Barcelona \\ Rebut: 4-11-2014 \\ Acceptat: 27-3-2015
}

L'ensenyament de la música tradicional i popular: una proposta multidisciplinària per al seu estudi

Resum. El present estudi vol mostrar els diversos elements que intervenen en l'ensenyament d'un estil musical, la música tradicional i popular, en un territori concret, a Catalunya, des de l'òptica etnomusicològica, pedagògica $i$ psicosocial. Actualment els llibres, articles i recerques que tracten sobre la música tradicional i popular catalana transmeten coneixement a partir d'una mirada bàsicament etnomusicològica. Aquesta mirada es vol ampliar cap a dos punts de vista més: el pedagògic i el psicosocial. Aquest article pretén mostrar un marc teòric bàsic per a analitzar el fenomen de la música tradicional i popular des d'una òptica multidisciplinària, necessària per a poder caracteritzar-ne els agents, contextos, usos i ensenyament. Per aquests motius es planteja descriure $i$ analitzar les metodologies de l'ensenyament de la Música Tradicional i Popular a Catalunya i caracteritzar psicològicament $i$ social els agents que hi intervenen (intèrprets, professorat i estudiants), com també proposar millores en l'ús $i$ en l'ensenyament de la música tradicional en els contextos d'educació formal i no formal.

Paraules clau: música tradicional i popular, etnomusicologia, pedagogia, psicologia, sociologia

Studying the teaching of traditional and popular music: a multidisciplinary proposal

Summary. This study is an attempt to shed light upon the various factors that influence the way a specific style of music, namely folk and traditional music, is taught in a specific territory, Catalonia, and to do so bringing to bear ethnomusicological, pedagogical and psychosocial perspectives. As of now, the books, articles and other research on Catalan traditional and popular music employ what is essentially an ethnomusicological approach to the transmission of knowledge on the topic. The intention here is to expand the method used to include two additional perspectives: pedagogical and psychosocial standpoints. The aim of this article is to provide a basic theoretical framework for the analysis of the phenomenon of traditional and folk music using a multidisciplinary approach, one that must be employed so as to characterize the agents involved in its teaching, as well as the associated contexts and practices. Thus, the purpose here is to describe and analyse the methods used in the teaching of Traditional and Folk Music in Catalonia and to provide a psychological and sociological characterization of the agents involved (musicians, teachers and students), as well as to propose possible improvements in teaching practice in the field of traditional music, in both formal and informal educational contexts.

Keywords: Traditional and folk music, ethnomusicology, pedagogy, psychology, sociology

Correspondència

Josep Gustems

Edifici de llevant 3a planta,

Pg. Vall d'Hebron, 171

08035 Barcelona

Email: jgustems@ub.edu 


\section{Introducció}

Fer música és una manifestació social i col-lectiva que cada poble, ètnia o grup social utilitza per a expressar-se (Blacking, 1994). Durant la història de la humanitat, els humans han exterioritzat de diverses maneres el fet de fer música. Aquesta varietat en l'expressió ha generat els diferents gèneres o estils musicals.

Podem definir la música tradicional i popular d'una col-lectivitat social concreta, en aquest cas la catalana (Aviñoa, 2007; Crivillé, 1983; Mayol \& Pujol, 2011; Rövenstrunck, 1979), com aquella música que:

- sona amb instruments autòctons característics (tenora, gralla, flabiol i tamborí...);

- sona en agrupacions tradicionals i populars pròpies (cobla, grup de grallers, grup d'havaneres...);

- sona en formes o estructures formals específiques (sardana, ball pla, jota...);

- sona en un context determinat (La Patum de Berga, La Gala de Campdevànol, el Toc de Castells...);

- sona amb línies melòdiques i patrons rítmics típics.

A més dels elements sonors que la fan característica i funcional d'un territori contextualitzat a nivell social, s'ha pogut observar, estudiar i definir la variabilitat de la música tradicional (Crivillé, 1990; Marcel-Dubois, 1960) com el fenomen que fa que la música tradicional i popular no sigui estàtica, sinó que vagi variant, mutant, canviant i d'aquesta manera es mantingui viva. El temps o l'edat de l'informant, el desplaçament de l'informant, els materials registrats dins o fora del context, el repertori vocal o instrumental, el trasllat del repertori individual a col-lectiu i viceversa i l'impacte amb els altres gèneres són els factors que nodreixen aquesta variabilitat.

La transmissió de la música tradicional sovint s'ha fet de manera generacional -de pares a fills, de generació en generació- i fora dels entorns reglats d'ensenyament i aprenentatge. A partir de la segona meitat del segle xx (Pujol, 2014) es detecta a Catalunya una pèrdua sonora en aquesta transmissió i sorgeix la necessitat de potenciar el seu ensenyament-aprenentatge. S'inicia des de l'entorn no reglat, però, de mica en mica, es comença a estructurar el seu ensenyament fins a aconseguir uns estudis reglats de grau professional i superior (Pujol \& Gustems, 2014).

Actualment a Catalunya conviuen ambdós ensenyaments: el reglat i el no reglat. Es pot aprendre

Figura 1.

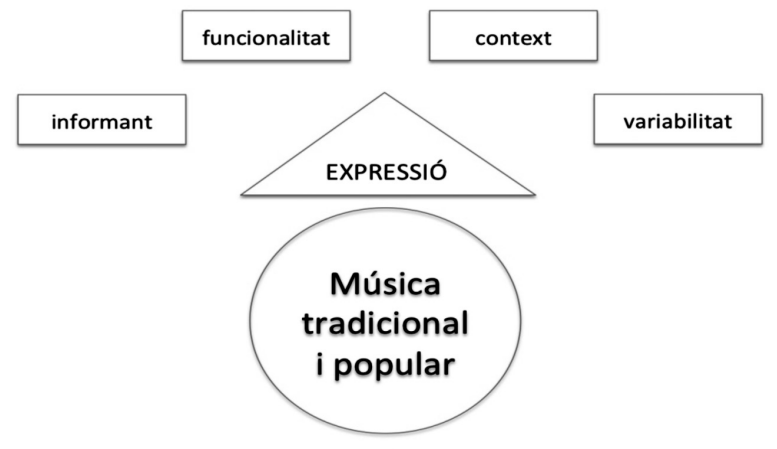

música tradicional i popular en entorns reglats (conservatoris professionals i Escola Superior de Música de Catalunya, ESMUC) i en entorns no reglats (escoles de música i altres llocs amb altres noms no relacionats amb el d'escoles de música (Aula de Música Tradicional i Popular, Centre Artesà Tradicionàrius, Aula de sons, Colla gegantera, escoles d'estiu, cursos, jornades...).

Segons Colom (2005), s'entén per entorn formal aquell que forma part del sistema educatiu institucional amb una graduació cronològica i una estructura jeràrquica. Segons Coombs i Ahmed (1974), s'entén per entorn no formal aquella activitat educativa organitzada fora del sistema educatiu vigent, que facilita la formació en aprenentatges concrets. Els mateixos autors defineixen entorn informal com un procés que dura tota la vida, en el qual les persones adquireixen coneixements habilitats, actituds i maneres de discernir mitjançant les experiències diàries i la seva relació amb el medi. S'anomena ensenyament reglat aquell que condueix a l'obtenció d'un títol oficial o homologat (conservatoris professionals i conservatoris superiors) i ensenyament no reglat aquell a través del qual s'obté un certificat o títol, anomenat títol propi, que no és ni oficial ni homologat. Aquests entorns d'aprenentatge de la música tradicional i popular catalana es nodreixen d'una gran varietat d'alumnes que comprenen franges d'edat molt àmplies, des de nens fins a persones adultes, la qual cosa fa que l'aprenentatge s'enriqueixi gràcies a la pràctica individual, grupal, entre iguals, intergeneracional i intranivells.

Aquesta característica dual, pel que fa a l'ensenyament reglat i no reglat, demana, doncs, de fer un estudi en profunditat sobre com s'ensenya i com s'aprèn actualment aquest estil de música, qui se sent atret per aquest tipus d'aprenentatges, quines competències personals i psicosocials permeten que un músic acabi inserint-se en el món laboral de la música tradicional i popular.

Per poder respondre a aquestes preguntes ens caldrà observar elements com la memòria, la motivació, la procedència, l'edat, el gaudi, l'escolta en grup, els instruments, el repertori..., però també fixar-nos en la incidència d'elements psicosocials dels intèrprets, professors i alumnes de la tradició oral o popular, com ara característiques de personalitat (per ex., inhibició, introversió, cooperació, sociabilitat, assertivitat, respecte, sensibilitat, impulsivitat...), dificultats d'integració social, lideratge, vergonya, capacitat d'improvisar i crear en directe, aprenentatge in situ, aprenentatge en grup, tutories entre iguals, rols socials, presència de trets psicopatològics, etc.

Estudiar aquest fenomen tenint en compte aquestes dimensions psicosocials pot ser una bona oportunitat per entendre quins poden ser els elements que caracteritzen l'ensenyament i l'aprenentatge de la música tradicional i popular, com també els trets més característics, a nivell psicològic i social, dels músics que treballen en aquest àmbit. Aquest article, que forma part d'un extens treball doctoral, pretén mostrar un marc teòric bàsic per a analitzar el fenomen de la música 
tradicional i popular des d'una òptica multidisciplinària, necessària per a poder caracteritzar-ne els agents, contextos, usos i ensenyament.

\section{L'etnomusicologia i l'estudi de la música tradicional i popular}

Des de sempre, l'home s'ha interessat per la música d'altres homes i d'altres cultures però és en el Romanticisme quan apareixen les primeres monografies al voltant de la cultura musical no occidental, essent Baker (1882) un dels primers que fa atenció a la música en una observació etnogràfica (Nettl, 1992).

La primera vegada que s'utilitza el mot folklore és en un article de l'arqueòleg anglès $W$. Thoms, l'any 1846, en la revista The Ateneum, en el qual proposava col-leccionar i estudiar antigues tradicions populars de temàtica àmplia. L'ambigüitat del terme folklore fa que calgui buscar altres termes com ara demologia, demosofia, demopedia, volkslehre, que puguin explicar millor la ciència que estudia el saber que va acumulant l'home en relació al seu entorn natural, social, cultural i polític i que té com a objecte, base i camp d'acció les diferents manifestacions de l'activitat popular i tradicional.

La problemàtica torna a aparèixer quan aquesta ciència ha de delimitar el seu camp d'acció: medi rural vers medi urbà. Malgrat la controvèrsia, el folklore és la «ciència que recull i estudia el saber tradicional, collectiu i anònim dels pobles civilitzats» i es deixa per a l'etnografia «l'estudi dels pobles naturals, sense lletra o primitius» (Crivillé, 1983, p. 18).

A finals del segle xix i gràcies a la necessitat d'entendre altres manifestacions musicals descobertes amb motiu dels territoris colonitzats pels europeus, l'augment del sentit nacionalista, els moviments migratoris i l'interès pels elements exòtics, neix allò que més tard s'anomenarà «etnomusicologia», com a branca de la musicologia. L'etnomusicologia esdevé disciplina científica gràcies a dos fets culturals que l'hi donen suport tecnològic: la invenció del fonògraf per T. A. Edison, l'any 1877, i la creació d'un sistema científic per dividir els intervals musicals en parts més petites, per l'acústic i fonètic A. J. Ellis (Myers, 2001).

A la primera meitat del segle $\mathrm{xx}$ aquest enfocament pren rellevància gràcies a l'Escola de Berlín, liderada per a E. M. von Hornbostel i integrada per C. Sachs (que, juntament amb Hornbostel, realitza l'estudi i la classificació dels instruments musicals del món el 1914), C. Stumpf (creador de l'Arxiu fonogràfic de Berlín el 1905) i A. Abraham (físic que l'ajuda en els enregistraments), els quals realitzen valuosos treballs exploratoris (Grebe, 1976).

En un inici, l'etnomusicologia s'identificà amb la musicologia comparada, que es basa en la comparació d'obres musicals, especialment cançons folklòriques, de diversos pobles de la terra (Adler, 1885), i la seva classificació segons les diverses estructures formals. No obstant això, el primer a utilitzar el terme etnomusicologia és Kunst (1950), que el fa servir com a subtítol d'un llibre perquè considera que és més adequat que el de musicologia comparada, i ho fa delimitant l'objecte de l'etnomusicologia en la música tradicional i els instruments de totes les cultures de la humanitat (Morales, 2003), en contraposició a Nettl (1964), que sosté que aquesta ciència només tracta amb la música dels pobles fora de la civilització occidental. Merriam (1964) la definia com l'estudi de la música en la cultura, o sigui, l'estudi dels sistemes musicals del món, sense distinció entre la música culta i la música popular. Hood (1971) afegeix que, a més a més d'observar el fenomen musical, també ha d'observar el fenomen físic, psicològic, estètic i cultural de tots els gèneres artístics existents. Aquest serà el nostre punt de vista i el nostre posicionament acadèmic enfront d'aquesta matèria d'estudi.

En la dècada de 1970, la investigació etnomusicològica comença a veure la importància d'una visió equilibrada entre les persones que pertanyen o no a la cultura estudiada, aportant la dimensió interior-exterior (èmica-ètica) en les recerques, i és en els anys vuitanta quan es considera que cal tenir també en consideració la personalitat i el bagatge de l'investigador, posicionament clarament instaurat en el paradigma interpretatiu tant en voga.

Si en un començament l'etnomusicologia tenia el seu focus d'atenció en les músiques no europees o foranes, fou a finals de 1970 i a causa de les restriccions econòmiques, que l'àmbit de treball es traslladà més a prop, començant a estudiar les músiques tradicionals i populars de pobles occidentals i locals (Campbell, 2013). Aquesta evolució de l'etnomusicologia es pot observar també a Catalunya, si comparem treballs de dècades diverses, com, per exemple, l'Obra del Cançoner Popular (1922 a 1936) i els enregistraments sonors i els reculls de partitures del Centre de Promoció de la Cultura Popular i Tradicional Catalana, del Departament de Cultura de la Generalitat de Catalunya (1993 a 2012). Tant en uns materials com en els altres s'hi troba la descripció de l'entorn, la seva funcionalitat, la transcripció musical i les dades de l'informant.

Segons Frechina (2006), les músiques tradicionals i populars són unes pràctiques, unes formes de «ser» sonorament en grup. Des d'un punt de mira històric i social, proposa els següents estadis cronològics de la música tradicional i popular a Catalunya:

1. Configurat per pràctiques tradicionals residuals de gent del poble que conserven el patrimoni.

2. A la Renaixença; es treu la música tradicional i popular del seu entorn i se'n fa un espectacle (Sección Femenina, esbarts, ...) provocant la desaparició de l'esdeveniment col-lectiu.

3. Com a resposta al moviment folk americà i europeu, apareix un moviment urbà de retrobament amb la memòria rural del primer estadi, on es viu la música tradicional com a vivència actual, modernitzadora, útil.

4. Utilització de la música tradicional sense complexos, sense voler-la modernitzar; senzillament s'agafa i s'utilitza. 
Martí (1996) és molt crític en la proliferació del fenomen tradicional i popular a Catalunya, ja que sosté que sota el terme «tradició» s'està fent una utilització de la música tradicional, i dels seus entorns i funcions, lluny del que segurament era, donant un valor sobreafegit a tot allò que es considera rural o procedent de la tradició oral. Aquest fenomen de folklorització, a causa de la necessitat de fixar el producte musical, utilitza l'últim estadi (Sachs, 1948) de la cadena del desenvolupament de la comunicació musical, la música enregistrada, fet que provocarà que desaparegui una de les característiques principals de la música tradicional: la variabilitat (Martí, 1996).

El treball de camp, el procés d'observació -participant-hi o no-i la transcripció continuen essent les tres activitats principals de l'etnomusicòleg, tot i que, si en un inici de l'etnomusicologia l'objectiu era transcriure exactament la manifestació sonora musical per tenir-ne un repertori, com hem vist, en l'actualitat, a més a més de la transcripció exacta o del registre sonor fidel, aquests esdevenen mitjans gràfics a partir dels quals es pot discutir, dissertar i investigar el perquè succeeixen determinats esdeveniments musicals.

Aquesta mirada etnomusicològica més àmplia afavoreix tant la música com les persones que la fan, oferint, a més a més del coneixement musical, un coneixement històric-sociopersonal més ampli, fet que obre aquest coneixement als pedagogs musicals o músics interessats en com s'aprèn i s'ensenya a fer aquesta música.

Campbell (2013) explica l'aportació que fa Booth (1986), mestre d'escola pública i instrumentista de tabla, en utilitzar el mètode etnomusicològic en la seva tesi doctoral quan estudia les tècniques pedagògiques dels mestres instrumentistes de l'Índia. Per fer-ho, realitza la descripció de conductes verbals i no verbals, i de l'ambient de la classe, així com transcripcions de fragments musicals de les interaccions entre mestre $i$ alumne. Holmes (1990), mestra d'escola pública i violinista, utilitza el mateix mètode per a explorar, com a observadora participant, les tècniques audioorals d'un violinista que ensenya música a principiants. Aquesta observació la condueix a l'elaboració d'una plantilla per a l'entrenament auditiu que és aplicable en molts contextos d'ensenyament. També realitza transcripcions de les sessions de la classe que mostren fragments musicals que fa el mestre, com a exemple, i les imitacions que en fan els estudiants, per arribar a fer-ho com ell.

\section{Ensenyar i aprendre música tradicional i popular}

Si s'hagués analitzat amb mirada pedagògica la transmissió de generació en generació, de la música tradicional i popular, segurament s'haurien pogut destacar els elements que la caracteritzen i que es podrien utilitzar en altres entorns d'aprenentatge de la música, però això ara només és possible saber-ho analitzant com es fa actualment i indagant en fonts documentals, o recorrent a la memòria de músics informants, encara
Figura 2. Aportacions del mètode etnomusicològic

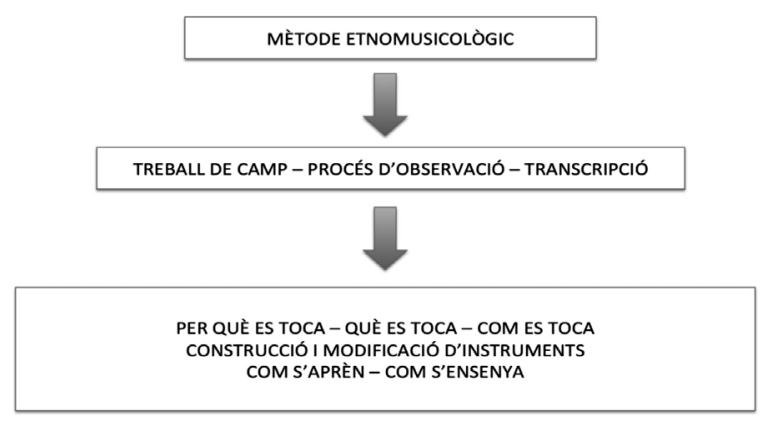

vius, per conèixer com es feia, per poder saber, deduir i explicar per què s'ha arribat a fer d'aquesta manera.

Alguns mètodes pedagògics musicals proposen l'inici de l'estudi de la música a partir del repertori vocal i instrumental de la música tradicional i popular de la pròpia cultura: serien els casos de Z. Kodály i I. Segarra a Hongria i a Catalunya respectivament. Ambdós consideraven que el fet d'iniciar-se en la música a partir del repertori que utilitza el poble en les seves manifestacions era més natural, ja que, com a integrant en potència d'una comunitat social, algunes de les peces del repertori ja s'havien percebut, i se'n percebrien més, d'una manera natural, afavorint així l'aprenentatge de la música (Riera, 1998; Szönyi, 1976). Ambdós autors utilitzaven el repertori tradicional i popular fonamentalment com a recurs pedagògic, sense atendre l'aprenentatge dels instruments propis i els seus entorns, musicalment més dèbils comparats amb els de la música clàssica.

Per estudiar l'ensenyament i aprenentatge de la música tradicional hem d'aproximar-nos-hi a partir de l'anàlisi de la metodologia educativa que li és pròpia, a partir d'uns fonaments, unes variables i unes tècniques determinades (Gustems, 2007). Els fonaments abasten les intencions educatives, les bases psicopedagògiques en què es recolza i el context educatiu en el qual s'insereix. Segons Coll (1990), la metodologia ha de ser coherent amb les intencions educatives reflectides en els objectius del programa i, segons Alsina (1997). la metodologia s'ha d'adequar al coneixement del que es vol ensenyar.

En les bases psicopedagògiques -procedents de la psicologia de l'educació, de la psicologia de l'ensenyament musical (Hargreaves, 1998; Lacárcel, 1995), de la pedagogia, quan els destinataris són infants i adolescents, i de l'andragogia (Knowles, 2001; Natale, 2003), quan es tracta d'adults-, cal destacar el constructivisme, en què l'activitat mental de cada individu sol i l'activitat interpersonal amb el professor i els altres companys és fonamental per a la construcció del coneixement (Antúnez, 1991), la metacognició, conèixer i reflexionar sobre l'adquisició del propi coneixement (Martí, 1995), l'estil cognitiu-dependent o independent de camp-o manera prevalent que tenim per percebre, processar i organitzar la informació (Torre, 1995), i els principis didàctics o lleis de l'aprenentatge, entre els quals, 
trobaríem, segons Palacios (1998), els següents: proximitat, ordenació, causalitat, contigüitat, adequació, espontaneïtat, activitat, freqüència, autocorrecció, eficiència, experiència, motivació intrínseca (curiositat, efectivitat, causació personal, característiques de l'activitat, autodeterminació o voluntat, i competència), motivació extrínseca (desviament de l'atenció, aprenentatge vicari del professor o del grup, i tècniques de modificació de la conducta), i emoció.

Descriure el context educatiu permet analitzar l'entorn on se situa l'ensenyament i tenir en compte aspectes socials, geogràfics, laborals, materials, característiques personals del professorat i l'alumnat (edat, nombre d'alumnes...), l'espai físic, horaris, etc.

Les variables són decisions preses en cada entorn educatiu, les quals, combinades entre elles, esdevenen macroestratègies d'organització pròpies de cada centre o institució. En l'anàlisi de l'ensenyament musical destaquen les següents: tipus d'activitats (Hargreaves, 1998), seqüències d'activitats, agrupaments d'alumnat (Baget, 1995), dinàmica de grup, (ambient, normes, rol dels alumnes i del professor) (Sloboda \& Davidson, 1998), organització de l'espai i del temps (Gustems \& Calderón, 2002), presentació dels continguts (Gardner, 1998) i ús dels materials didàctics (Bautista-Vizcaíno, 2003).

Les tècniques són l'àmbit de decisions que pren el professorat individualment en el moment de fer classe. Les més habituals serien aquestes: classe magistral, producció i presentació de treballs dels alumnes (Arts Propel, 1992), l'ensenyament tutoritzat, el mètode per projectes (Muñoz, 2002), el treball en grup (Vigotsky, 1979), el mètode Socràtic i la Dialogia, l'anàlisi de models, el mètode del descobriment o l'experiment, el mètode de cas, la solució creativa de problemes, el roleplaying, etc.

Les investigacions actuals en l'ensenyament i aprenentatge dels instruments musicals assenyalen tres perfils del professorat en la manera d'ensenyar: directe, interpretatiu i constructiu (Pérez Echeverría, Mateos, Pozo \& Scheuer, 2001). Aquestes tres maneres de fer classe englobarien des de característiques relacionades amb un total predomini de les instruccions per a l'estudiant, fins a instruccions donades per un professor com a reflexions generades a partir de la interacció i necessitats expressades per l'estudiant (Marín, Scheuer \& Pérez Echeverría, 2013).

El professor constructiu genera pràctiques docents que promouen i fomenten la reflexió i l'activitat metacognitiva de l'alumne en el seu propi aprenentatge (Pozo, Scheuer, Mateos \& Pérez Echeverría, 2006). Actualment es tendeix més cap aquest perfil de professor perquè fomenta:

- L'autonomia: guiant els alumnes en el moment de reflexionar sobre la seva pròpia pràctica, generant estratègies que els permeten emetre judicis i valoracions en relació a la seva pràctica, adquirint autonomia i control en relació al propi aprenentatge.

- La comprensió a través de la reflexió: la definició dels problemes i de les seves possibles solucions es poden interpretar com un procés de redescripció representacional (Karmiloff-Smith, 1994; Pozo, 2003; Pozo et al. 2006), que permet reconstruir i donar significat a la dificultats, entenent els motius de les millors solucions.

- L'automatització reflexiva de tècniques: la repetició apareix en el procés de la reflexió «en» $\mathbf{i}$ «sobre» l'acció com a resultat del procés reflexiu (Schön, 1992); s'aconsegueix un cert grau d'automatització, i també un control conscient sobre la pròpia acció, que portarà cap a una nova fase del procés d'automatització, sempre guiada per la reflexió.

- Una contínua autoavaluació: reflexionant en relació als encerts i als errors. Es tracta que l'alumne vagi adquirint una autonomia creixent en aquest aspecte, component essencial de la seva activitat metacognitiva.

En l'aprenentatge constructiu l'error esdevé un dels motors de l'aprenentatge, ja que indueix a una nova reflexió i comprensió, en contraposició a l'aprenentatge directe i reproductiu, en el qual el que es busca és evitar els errors (Torrado \& Pozo, 2006). Segons aquests autors, els trets més essencials de la pràctica constructiva en l'ensenyament instrumental són els següents: treballar amb els coneixements previs dels alumnes, fomentar la motivació necessària per a mantenir l'esforç, i la pròpia planificació i disseny de les activitats d'ensenyament i aprenentatge (Torrado \& Pozo, 2006).

Persson (1996) destaca que la relació amb la figura del mestre tutor o mentor durant els estudis musicals pot tenir profundes conseqüències, tant positives com negatives, vers la vida laboral del músic, ja que sovint al professor li costa orientar l'ensenyament cap a la persona en comptes de cap al producte. La característica d'efectivitat de la música tradicional i popular fa que les seqüències didàctiques de les classes vagin encaminades directament a un producte final. Aquest fet és rellevant i distintiu en relació a altres estils, provocant que el repertori és el que marca la tècnica que cal estudiar o adquirir, i no al revés, com sol passar en l'estudi de la música clàssica. L'objectiu de productivitat és un fenomen característic de la música tradicional i popular, en què l'aprenentatge es basa, a més a més del que s'aprèn a la classe, en el fet de tocar en el context en què l'expressió i l'experiència esdevenen variables i tècniques pedagògiques que retroalimenten el mateix procés d'ensenyament i aprenentatge, ja que el professor-tutor és present tant a l'aula com en el context.

Tot i que actualment sabem que l'aprenentatge de la música tradicional i popular desenvolupa l'afinació, la recerca del so característic de l'instrument, el fet de tocar de memòria, d'oïda i llegint, el fet de tocar tant individualment com en grup, la sincronia i el lideratge, a través d'un repertori tradicional, popular i de nova creació, es detecta que hi ha força variació, variabilitat i dispersió en la manera d'ensenyar.

Les fonts documentals també ens indiquen que hi ha pocs estudis que puguin mostrar, d'una manera objectiva i interrelacionada, els fonaments, les variables 
Figura 3. Aprenentatge música tradicional i popular

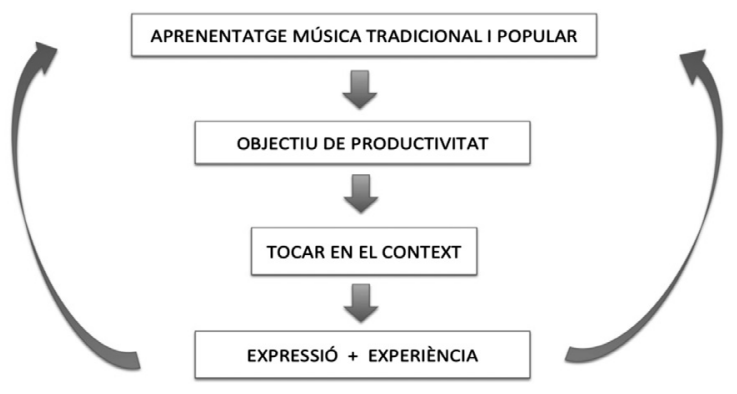

i les tècniques que s'utilitzen en l'aprenentatge de la música tradicional i popular a Catalunya, les característiques, en relació a la tipologia de professor, segons la pròpia manera d'ensenyar, les relacions entre el currículum i la demanda musical real i els elements que configuren el currículum ocult.

\section{A la recerca d'un perfil psicosocial dels agents de la música tradicional i popular}

L'ensenyament i l'aprenentatge de la música tradicional i popular esdevenen un objecte d'estudi en el qual la psicologia i la sociologia poden aportar valuoses mirades i metodologies de treball. En concret, destacarem els següents aspectes: els trets de personalitat com a factors que influencien l'èxit i la inserció dins el món de la música tradicional i popular; l'autoeficàcia i l'autoestima; els aspectes vinculats al gènere (sexe), i els aspectes vinculats als rols de lideratge i a la identitat social.

\section{Personalitat}

Les persones es poden caracteritzar segons una sèrie d'elements de caràcter bàsic, que anomenem trets de personalitat. Tot i haver-hi moltes teories i molts experts al llarg del segle xx que han tractat de definir-los, devem a R. B. Cattell, en els anys quaranta, la formulació de 16 patrons bàsics (l'anomenat $16 \mathrm{PF}$ - Personality Factors) extrets del lèxic que usava la gent per a definir-se, els quals actuarien com a pols (de manera que un individu tendeix més cap a un extrem que cap a un altre), i serien aquests: la calidesa respecte als altres, la intel-ligència i capacitat d'aprenentatge, l'estabilitat emocional, la seriositat, el domini sobre els altres, el grau de seguiment de la norma, la timidesa, la sensibilitat, la confiança, la imaginació, l'extraversió, la seguretat, l'obertura al canvi, la tendència a la solitud, el perfeccionisme, i el nerviosisme (Cattell, 1972).

Altres estudiosos, com Goldberg van agrupar aquests trets en cinc de bàsics (l'anomenat Big Five): obertura a l'experiència (que inclou la curiositat, l'estima per l'art i l'aventura); la consciència (que inclou un major sentit del deure i de la planificació); l'extraversió (que inclou el desig de companyia, una autoestima alta i energia vital); l'agradabilitat (que inclou l'empatia i la confiança) i el neuroticisme (que inclou la inestabilitat emocional).

La passió per les activitats (Chamarro, Martos, Parrado \& Oberst, 2011), concepte que actualment comença a ser objecte d'investigació empírica, fa referència a com es practica una activitat i a la manera en què la persona viu aquesta pràctica. Els models de passió que es proposen (Vallerand et al. 2003) són la passió harmoniosa (acceptació lliure de l'activitat apassionant) i la passió obsessiva (sobreidentificació amb l'activitat apassionant).

El suport i l'encoratjament dels pares, de la família més enllà dels progenitors -en què en el món rural esdevenen més forts que en el món urbà i amb més tradició per conservar els llaços familiars-, de les relacions entre iguals, els models de rol, els professors i les institucions, el fort concepte d'un mateix com a músic, i les estratègies personals que sustenten la perseverança i l'autodisciplina en un domini altament competiu, són factors que ajuden tant en l'estudi de l'instrument com en la decisió i transició cap a la professionalització (Creech et al. 2009).

\section{Autoeficàcia i autoestima}

Des de la Teoria Social Cognitiva, es defineix l'autoeficàcia com les creences en les pròpies capacitats per a organitzar i executar els cursos d'acció requerits que produiran determinats èxits i resultats (Bandura, 1997).

Cal considerar que les creences d'eficàcia d'una persona difereixen entre elles depenent de l'activitat o domini a la qual facin referència (Bandura, 1997). És a dir, que una persona pot sentir-se més o menys eficaç depenent de l'activitat concreta a la qual s'enfronti (Bandura, 1997; Salanova, Peiró \& Schaufeli, 2002), com seria en aquest cas el de la seva autoestima com a intèrpret musical, capacitat per a improvisar, habilitats de lectura a vista, de tocar d'oïda, coneixement de les noves tecnologies aplicades a la interpretació o a la pedagogia en el cas del professorat, etc.

En aquest marc d'autoeficàcia, Bandura (1997) ja va assenyalar algunes estratègies actives per a desenvolupar-la: l'orientació cap a l'èxit i els assoliments, la persuasió verbal i l'aprenentatge vicari, referint-se a l'exemple que adopten determinades persones, músics i professors que esdevenen models a seguir a causa del seu carisma, tant personal com musical.

\section{Gènere (sexe)}

Volem destacar la variable sexe per damunt d'altres, ja que el model d'expectativa-valor proposat per Eccles (2005) estableix la importància de la confiança en l'autoeficàcia personal, la motivació i el rendiment acadèmic en l'elecció de les opcions educatives i professionals en funció del gènere, per sobre d'altres capacitats i habilitats demostrades. Part de les diferències de gènere trobades podrien explicar-sota l'enfocament d'aquest model- el fet que les dones solen tenir unes 
expectatives més realistes sobre les seves habilitats, mentre que els homes sobreestimen les seves, de manera que una excessiva autoconfiança en homes pot portar com a resultat un rendiment acadèmic més baix, mentre que en dones la presència de més autoconfiança en si mateixes incrementa les seves possibilitats d'èxit (Watt, 2005).

Iniciar-se a fer música és quelcom ben vist a nivell social, tant per als nens com per a les nenes, pels beneficis que comporta de cara al desenvolupament integral de la persona. La realitat del món musical professional que hem observat, però, ens permet pensar que, a mesura que la persona creix, hi ha una tendència majoritària de les noies a abandonar aquests estudis per uns altres. Despins (1996) indaga sobre la variable sexe/gènere i el cervell en les diverses formes de l'activitat musical, des de l'asimetria dels hemisferis cerebrals. Exposa com la variable sexe influeix en el desenvolupament de l'asimetria hemisfèrica, en les relacions inter i intrahemisfèriques i en la bilaterització hemisfèrica. Expressa que "No hay burla al señalar la mayor capacidad de aprendizaje de la música que manifiestan las niñas en ese contexto verbalizante" (hemisferi esquerre $)^{1}$ (Despins, 1996, p. 67).

En el mateix sentit, Green (2001) desenvolupa la idea de la utilització dels conceptes música clàssica i música popular ${ }^{2}$, no tant com a significant d'estils musicals sinó com a pràctiques musicals marcades pel gènere. Curiosament, aquesta autora relaciona gènere, tempo de la música i estil musical amb certs prejudicis, caracteritza la música clàssica com a música lenta i, per tant, afirmadora del perfil femení, actitud de conformitat, i ho fa en contraposició a la música popular, com a música més ràpida $\mathrm{i}$, per tant, interruptora de la feminitat, actitud de disconformitat. Aquest punt de vista, tot i tenir certa base històrica i simbòlica és clarament restrictiu i aliè als nostres temps i a la coeducació de la nostra societat. Fins i tot relaciona la creativitat amb l'obediència quan exposa la idea que els nens són més dolents i rebels però també més creatius, i les nenes són més bones i conformistes, amb actituds capacitants i cooperativistes, explicant que les noies que són rebels no ho poden demostrar, ja que trencarien la feminitat. No obstant les nostres diferències de posicionament, creiem interessant citar la seva classificació de les activitats musicals en relació a la feminitat:

- l'afirmació de la feminitat: dones que canten, dones que capaciten els altres.

- de l'afirmació a la interrupció de la feminitat: dones que toquen instruments.

- amenaces a la feminitat: dones que componen i improvisen.

La citació de Walkerdine continua aquesta illustració quan diu:

\footnotetext{
${ }^{1}$ L'aclariment entre parèntesis és dels autors.

${ }^{2}$ En l'entorn anglosaxó, quan es parla de música popular es fa referència a la música anomenada pop.
}

«Las estimaciones que reconocen ciertos éxitos de las chicas los atribuyen al seguimiento de reglas y al aprendizaje memorístico, que se distinguen de la comprensión e, incluso se oponen a ella. De ahí que nieguen ese éxito en el momento en que lo anuncian: las chicas "se limitan" a seguir reglas; son muy buenas en comparación con los "desobedientes" chicos, que pueden "romper moldes" (efectuar saltos conceptuales) (...)» (Walkerdine, 1990, segons Green, 2001, p.189).

O’Neill (1997) explica com la tria dels instruments es veu condicionada pels estereotips de gènere, afirmació que podria documentar amb moltes experiències de vida d'instrumentistes en actiu.

Cal afegir a aquesta llista altres aspectes que condicionen el fet de fer música quan s'és adult (Burness, 1975) i que poden tenir diferents conseqüències segons el sexe:

- Horaris poc convencionals; es treballa quan tothom està de festa, dedicant-hi moltes hores, fora i lluny de casa.

- Entorn molt masculí.

- Dificultat de conciliació amb la maternitat i criança dels fills.

- Comprensió, per part de la família, d’un ofici expressiu i expositiu.

Actualment, a Catalunya, la dona és present en moltes agrupacions de música tradicional i popular: cobla (Ayats, Costal \& Rabaseda, 2009), grups de grallers, grups d'acordions, etc.

\section{Rols de lideratge}

El rol és el comportament que s'espera d'una persona en un context social determinat. De la bona distribució, coneixement i utilització dels rols innats dels membres d'un equip en depèn, en certa mesura, el bon funcionament de l'equip. Aquests rols d'equip (Belbin, 1995) poden classificar-se en tres grans categories:

- rols d'acció: Impulsor, Implementador, Finalitzador. - rols socials: Coordinador, Investigador de recursos, Cohesionador.

- rols mentals: Cervell, Monitor avaluador, Especialista.

Fer música en grup és un treball en equip i per això resulta molt interessant conèixer quins són aquests comportaments en una mostra rellevant dels músics que es dediquen a la música tradicional i popular a Catalunya.

El lideratge és una paraula clau en la psicologia social i en les ciències de la conducta (Bernal \& Gil, 2000). En estudiar els grups i el seu comportament, el tema del lideratge és important, ja que tot grup tendeix a l'establiment d'un líder, es tracti d'un lideratge individual o compartit. En parlar de lideratge, es fa referència al líder, al grup i al seu funcionament. Conèixer els diferents estils de lideratge (autoritari, coach, democràtic, etc.) dels membres d'un grup o d'un director de formació pot ajudar a establir canals de comunicació, de treball i regulació de les relacions per esdevenir un grup estable (Goleman, 2014). 


\section{Identitat social}

Per demostrar l'autenticitat en relació a una música s'utilitzen paraules com essència, essencial, real, actual, d'abans, d'arrel, tribal, aborigen, ancestral, genuïna, de la terra... (Taylor, 1997), però l'autenticitat d'una música no és deguda a la música, sinó a la persona que fa aquella música (Moore, 2002). L'autenticitat és allò oposat a entreteniment, a comercial (Grossberg, 1992), a modernitat (Boyes, 1993). Segons Gilbert i Pearson (1999), el paper fonamental del cantant era representar la cultura d'on procedia. L'autenticitat està avalada per l'honestedat en l'experiència, pel missatge sincer, i és la comunitat, formada per la suma de subjectivitats, qui valida l'autenticitat social. Aquesta autenticitat es construeix a partir del que han fet els predecessors, sense total llibertat a causa de l'audiència i fugint del pretès universalisme del llenguatge musical, ja que prové d'una arrel i, per tant, no pot ser fet de qualsevol manera. El repertori de cançons i músiques tenen identitat, essent aquesta la clau per a l'experiència (Moore, 2002).

\section{Conclusions}

A grans trets i fent una possible síntesi dels aspectes a considerar per tal d'abordar l'ensenyament de la música tradicional i popular a Catalunya, es podria dir que els elements que configuren l'ensenyament i l'aprenentatge de la música tradicional i popular és possible que estiguin relacionats amb habilitats:

- cognitives, d'aprendre a tocar un instrument mitjançant un repertori específic que, a la vegada, ensenyarà llenguatge musical i cultura a través d'elaborar artesanalment i emetre un so específic que identifica; - personals, relacionades amb un augment de l'autoestima i el gust que produeix fer música;

- socials, el fet de pertànyer a un grup i sentir-te part d'ell. Robinson (2009) explica com l'escriptora Meg Ryan considera molt important coincidir amb un grup de persones que veuen el món de la mateixa manera que tu, ja que això permet sentir-se còmode i possibilita treure el millor de cada una. El que connecta a un grup de persones, que Robinson anomena tribu, és el compromís comú pel que sents quan has nascut en aquest grup.

Figura 4.

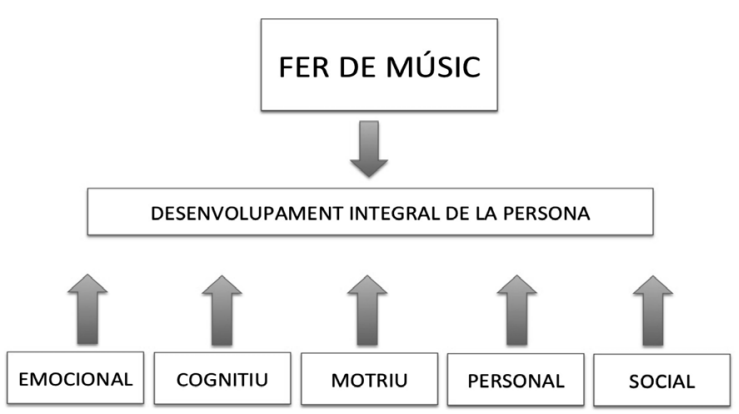

Per tot això, es proposa l'aplicació a una mostra rellevant de casos de les eines metodològiques adients que permetin obtenir dades fiables per a caracteritzar i fer propostes de millora de l'ensenyament de la música tradicional i popular a Catalunya.

Nota dels autors: Aquest estudi està finançat per un ajut a la recerca de l'ARCE (Agrupació en Recerca de Ciències de l'Educació), convocatòria 2013, i forma part d'una recerca doctoral a la Universitat de Barcelona.

\section{Referències}

Adler, G. (1885). Umfang, Methode und Ziel der Musikwissenschaft. Vierteljahrschrift fur Musikwissenschaft,1,5-20.

Alsina, P. (1997). El área de educación musical. Barcelona: Graó.

AMTP. (2009). Aula de Música Tradicional i Popular. Recuperat de http://www.amtp.cat

Antúnez, S. (1991). Del projecte educatiu a la programació d'aula. Barcelona: Graó.

Arts Propel (1992). Harvard: Hardvard Project Zero.

Aviñoa, X. (Dir.) (2007). Història de la música catalana, valenciana i balear, vol. 6. Música popular i tradicional. Barcelona: Edicions 62.

Ayats, J., Costal, A. \& Rabaseda, J. (2009). Sardanes. Girona: Diputació de Girona-Fundació Caixa Girona.

Baget, A. (1995). Reflexiones sobre las clases colectivas. Quodlibet, 2, 114-115.

Baker, T. (1882). Über die Musik der nordamerikanischen Wilden. Leipzig: Breitkopf \& Hairtel.

Bandura, A. (1997). Self-efficacy: the exercise of control. New York: Freeman.

Bautista-Vizcaíno, F. (2003). Creación e investigación en el campo de la tecnología educativa: el MAEI (Método Audiovisual para la Enseñanza Instrumental). Eufonía, 28, 80-88.

Belbin, M. (1995). Roles de equipo en el trabajo. Bilbao: Universal.

Bernal, J. L. \& Gil, M. T. (2000). Escuelas aceleradas. Cuadernos de Pedagogía, 285, 33-39.

Blacking, J. (1994). Fins a quin punt l'home és músic? Vic: Eumo.

Booth, G. (1986). The oral tradition in transition: Implications for music education from a study of north Indian tabla transmission. Kent: Kent University Press.

Boyes, G. (1993). The imagined village: culture, ideology and the english folk revival. Manchester: Manchester University Press.

Burness, J. (1975). Bars rest. London: Paterson's Publications.

Campbell, P. S. (2013). Etnomusicología y Educación Musical: Punto de encuentro entre música, educación y cultura. Revista Internacional de Educación Musical, 1, 42-51.

Cattell, R. B. (1972). The 16 P.F. and basic personality structure: A reply to Eysenck. Journal of Behavioural Science, 1(4), 169-187.

Chamarro, A., Martos, V., Parrado, E. \& Oberst, U. (2011). Aspectos psicológicos del baile: Una aproxi- 
mación desde el enfoque de la pasión. Aloma. Revista de Psicologia, Ciències de l'Educació i de l'Esport, 29, 341-350.

Coll, C. (1990). Un marco de referencia psicológico para la educación escolar: la concepción constructivista del aprendizaje y de la enseñanza. A C. Coll, J. Palacios \& A. Marchesi (comps.), Desarrollo psicológico y educación, II. Psicología de la Educación (pp. 435453). Madrid: Alianza.

Colom, A. J. (2005). Continuidad y complementariedad entre la educación formal y la no formal. Revista de Educación, 338, 9-22.

Coombs, P. H. \& Ahmed, M. (1974). Attacking rural poverty: how non formal education can help. Baltimore: Johns Hopkins University Press.

Creech, A., Papageorgi, I., Duffy, C., Morton, F., Haddon, E., Potter, J., de Bézenac, C., Whyton, T., Himonides, E. \& Welch, G. F. (2009). From music student to professional: The process of transition. British Journal of Music Education, 25(3), 315-331.

Crivillé, J. (1983). El folklore musical. Historia de la música española, vol. 7. Madrid: Alianza editorial.

Crivillé, J. (1990). De la variabilidad en la música de tradición oral. Algunas reflexiones sobre el tema. De Musica Hispana et Aliis. Vol. II. Santiago de Compostela: Universidad de Santiago de Compostela.

Despins, J. P. (1996). La música y el cerebro. Barcelona: Gedisa.

Dumas de la Roque, P. (2012). La escucha, es la vida. Barcelona: Altom.

Eccles, J. (2005). Studying the development of learning and task motivation. Learning and Instruction, 15(2), 161-171.

Frechina, J. V. (2006). Vells i nous camins per a la música tradicional. A J. Domenge (coord.), El patrimoni musical (I). Curs de cultura popular i tradicional (pp. 77-87). Manacor: Patronat de l'Escola Municipal de Mallorquí.

Gardner, H. (1998). Inteligencias múltiples. Barcelona: Paidós.

Gilbert, J. \& Pearson, E. (1999). Discographies: dance music, culture, and the politics of sound. Oxon: Routledge.

Goleman, D. (2014). Liderazgo. Barcelona: de Bolsillo.

Grebe, M. E. (1976). Objeto, métodos, técnicas de investigación en etnomusicología: algunos problemas básicos. Revista Musical Chilena, 133, 5-27.

Green, L. (2001). Música, género y educación. Madrid: Morata.

Grossberg, L. (1992). We gotta get out of this place: popular conservatism and postmodern culture. London: Routledge.

Gustems, J. (2007). Aproximación metodológica a la didáctica de los instrumentos musicales. Apuntes para un curso de doctorado. Recuperat de http://diposit.ub.edu/ dspace/bitstream/2445/11522/3/apuntes_doctorado_aproximacion_instrumentos_musicales.pdf

Gustems, J. \& Calderón, C. (2002). Enseñanza presencial y virtual en la educación musical. Eufonía, 25, 109-115.
Hargreaves, D. J. (1998). Música y desarrollo psicológico. Barcelona: Graó.

Holmes, R. (1990). A model of aural instruction examined in a case of fiddle teaching. Washington: Washington University.

Hood, M. (1971). The Ethnomusicologist. Nova York: McGraw Hill.

Karmiloff-Smith, A. (1994). Más allá de la modularidad. Madrid: Alianza.

Knowles, M. S. (2001). Andragogía. El aprendizje de los adultos. México: Oxford University.

Lacárcel, J. (1995). Psicología de la música y educación musical. Madrid: Visor.

Marcel-Dubois, Cl. (1960). Musique populaire française. Encyclopédie de la musique. Paris: Fasquelle.

Marín, C., Scheuer, N. \& Pérez Echeverría, M. P. (2013). Formal music education not only enhances musical skills, but also conceptions of teaching and learning: a study with woodwind students. European Journal of Psychology of Education, 28, 781-805. doi: 10.1007/ s10212-012-0140-7

Martí, E. (1995). Metacognición: Entre la fascinación y el desencanto. Infancia y aprendizaje, 72, 9-32.

Martí, J. (1996). El folklorismo. Uso y abuso de la tradición. Barcelona: Ronsel.

Mayol, J. M. \& Pujol, M. A. (2011). Requetetxec. Descobrim els instruments $i$ grups instrumentals dels Països Catalans. Barcelona: Generalitat de Catalunya.

Merriam, A. (1964). The antropology of music. Evanston: Northwestern University Press.

Moore, A. (2002). Authenticity and Authentication. Popular Music, 21(2), 209-223.

Morales, E. (2003). La etnomusicología, definición y objeto de estudio. Gaceta Universitaria, 21.

Muñoz, J. R. (2002). La vuelta al mundo musical. Eufonía, 26, 53-61.

Natale, M. L. (2003). La edad adulta: una nueva etapa para educarse. Madrid: Narcea.

Nettl, B. (1992). Recent directions in Ethnomusicology. A H. P. Myers (ed.). Ethnomusicology: An Introduction (pp. 375-399). London: Mc Millan Press.

O’Neill, S. (1997). Gender and music. A D. J. Hargreaves $\&$ A. C. North (eds.), The social psychology of music (pp. 46-60). Oxford: Oxford University Press.

Palacios de Sans, M. (1998). La Didáctica aplicada a la enseñanza del instrumento. Revista electrónica de LÉEME, 2.

Pérez Echeverría, M. P., Mateos, M., Pozo, J. I. \& Scheuer, N. (2001). En busca del constructivismo perdido: concepciones implícitas sobre el aprendizaje. Estudios de Psicología, 22(2), 155-173. doi:10.1174/02109390 1609479.

Persson, R. S. (1996). The Maestro Music Teacher and Musicians' Mental Health. Toronto: American Psychological Association.

Pozo, J. I. (2003). Adquisición de conocimiento: cuando la carne se hace verbo. Madrid: Morata.

Pozo, J. I., Scheuer, N., Mateos, M. \& Pérez Echeverría, M. P. (2006). Las teorías implícitas sobre el aprendi 
zaje y la enseñanza. A J. I. Pozo, N. Scheuer, M.P. Pérez Echeverría, M. Mateos, E. Martín \& M. de la Cruz (Eds.), Nuevas formas de pensar la enseñanza y el aprendizaje: Las concepciones de profesores y alumnos (pp. 95-132). Barcelona: Graó.

Pujol, M. A. (2014). La enseñanza y el aprendizaje de la música tradicional y popular en Cataluña: el caso del AMTP, CAT y los grupos de Castellers y Gigantes. Actas del Congreso CEIMUS III (pp. 405-422). Pozuelo de Alarcón: Enclave Creativa Ediciones.

Pujol, M. A. \& Gustems, J. (2014). La presencia de los instrumentos de música tradicional en la enseñanza superior en Cataluña (2001-2013). Recuperat de, http://hdl.handle.net/2445/57145

Riera, S. (1998). L'aportació pedagògica. A Ireneu Segarra. Mig segle de mestratge musical (pp. 37-55). Barcelona: Publicacions de l'Abadia de Montserrat.

Robinson, K. (2009). El elemento. Descubrir tu pasión lo cambia todo. Barcelona: Grijalbo.

Rövenstrunck, B. (1979). Singularitats de la cançó popular catalana. Barcelona: Clivis.

Sachs, C. (1948). Our Musical Heritage, a short history of music. New York: Prentice-Hall.

Salanova, M., Peiró, J. M. \& Schaufeli, W. (2002). Selfefficacy Specificity and Burnout among Information Technology Workers: An extension of the Job Demands-Control Model. European Journal on Work and Organizational Psychology, 11, 1-25.

Schön, D. A. (1992). La formación de los profesionales reflexivos. Barcelona: Paidós-MEC.

Sloboda, J. \& Davidson, J. (1998). El joven intérprete. Quodlibet, 10, 80-101.

Szönyi, E. (1976). La educación musical en Hungria a través del método Kodály. Budapest: Corvina.

Taylor, T. D. (1997). Global Pop: World Music, World Markets. New York: Routledge.

Torrado, J. A. \& Pozo, J. I. (2006). Del dicho al hecho: de las concepciones sobre el aprendizaje a la práctica de la enseñanza de la música. A J. I. Pozo, N. Scheuer, M. P. Pérez Echeverría, M. Mateos, E. Martín \& M. de la Cruz (Eds.), Nuevas formas de pensar la enseñanza y el aprendizaje: Las concepciones de profesores y alumnos (pp. 205-228). Barcelona: Graó.

Torre, S. de la (1995). L'error com a estratègia didàctica. A S. De la Torre (ed.) Conèixer per canviar (pp. 9-28). Barcelona: PPU.

Vallerand, R., Blanchard, C., Mageau, G. A., Koestner, R., Ratelle, C., Léonard, M. \& Gagné, M. (2003). Les passions de l'Âme: On Obsessive and Harmonious Passion. Journal of Personality and Social Psychology, 85(4), 756-767.

Vigotsky, L. S. (1979). El desarrollo de los procesos psíquicos superiores. Barcelona: Crítica.

Walkerdine, V. (1990). Schoolgirl Fictions. London: Verso. Watt, H. M. G. (2005). Explaining gendered math enrollments for NSW Australian secondary school students. New Directions for Child and Adolescent Development, 110, 15-29.

La enseñanza de la música tradicional y popular: una propuesta multidisciplinària para su estudio

Resumen. El presente estudio quiere mostrar los diversos elementos que intervienen en la enseñanza de un estilo musical, la música tradicional y popular, en un territorio concreto, en Catalunya, desde la óptica etnomusicológica, pedagógica y psicosocial. Actualmente los libros, artículos e investigaciones que tratan sobre la música tradicional y popular catalana transmiten conocimiento a partir de una mirada básicamente etnomusicológica. Esta mirada quiere ampliarse hacia otros dos puntos de vista: el pedagógico y el psicosocial. Este artículo pretende mostrar un marco teórico básico para analizar el fenómeno de la música tradicional y popular desde una óptica multidisciplinar, necesaria para poder caracterizar sus agentes, contextos, usos y enseñanza. Por estos motivos se plantea describir y analizar las metodologías de enseñanza de la Música Tradicional y Popular en Catalunya, y caracterizar psicológica y socialmente los agentes que intervienen (intérpretes, profesorado y estudiantes) y proponer mejoras en el uso y en la enseñanza de la música tradicional en los contextos de educación formal y no formal.

Palabras clave: música tradicional y popular, etnomusicología, pedagogía, psicología, sociología 